\title{
A Culture of Guns: Firearms a Key Feature of the Hemingway Narrative and Persona
}

\author{
Neil L. R. Tate \\ Associate Professor, Faculty of Letters, Tohoku Gakuin University 1-3-1 Tsuchitoi, Aobaku, Sendai City \\ Miyagi Prefecture 980-8511 Japan. \\ tgunick@yahoo.com
}

\begin{abstract}
Although scholars are fully cognizant of the fact that twentieth century American writer Ernest Miller Hemingway (1899-1961) enjoyed the shooting sports throughout his life, it has never been comprehensively analyzed in the corpus of criticism how deeply the writer incorporated firearms into many areas of his persona and psyche. Hemingway demonstrates a connection with firearms that extends beyond the realm of the mundane activities of sport and military-venturing into erotic fantasy, sexual fetishism, and symbolism. This intriguing area of research has only been assessed tangentially by anecdotal references. Ultimately, firearms manifest as a key feature in the life and culture of Hemingway and remain deeply woven into the tapestry of his narrative and the idiom of his discourse.
\end{abstract}

Keywords: Eroticism, Fetishism, Firearms, Hemingway, Narrative, Persona, Psyche

\section{INTRODUCTION}

In the nine decades of Hemingway criticism, scholars and critics have taken for granted that the writer was the quintessential man of active sports - a persona that Hemingway carefully groomed in the light of public attention-with firearms often taking a central role in both his life and narrative. Despite the many anecdotal associations of firearms with Hemingway and his articles in sports magazines on the topic, a comprehensive assessment of modern weapons in the life and fiction of Ernest Hemingway has never been fully accomplished, nor has it been properly addressed how deeply firearms were integrated into the writer's emotional persona and psyche. In the gun culture of Hemingway, firearms function in a variety of ways: design and function provide subtle information on character motivation; knowledge and ability an element of the protagonist hero; associated with pleasure and connected to erotic fetishism; as a measure of man; and as a problem solving tool. Furthermore, despite his keen knowledge and experience, the writer makes some fundamental errors in the handling of firearms.

\section{DISCUSSION}

Like most children growing up in the late nineteenth and most of the twentieth century in rural and semi-rural areas of America, Hemingway probably could not remember a time when firearms were not a part of his life. The famous photographs archived in the John F. Kennedy Library attest to the fact that Hemingway learned the use of firearms from an early age, and one very Norman Rockwell photo shows the young Ernest at age five standing on the prow of boat on the shore of Lake Walloon in northern Michigan while while holding a King air rifle (Calabi et al. 6). In another photo, teenager Ernest, looking like a hillbilly, holds a monster ten-gauge shotgun and a dead crow (7). Hemingway's life-long passion for the shooting sports blasts from the pages of many letters to friends and family, and he writes detailed discussions on guns for various situations. In a letter to Archibald Mac Leish dated November 1930, dictated to wife Pauline Pfeiffer while recovering his broken arm in a Billings hospital, Hemingway warns his friend to be wary over Mike Strater's knowledge of firearms and states: "As a matter fact, don't let anybody tell you anything about guns except old Pappy.... In other words, you can see that I'm getting to be an authority on guns. When I get started on guns we run out of paper, and 
A Culture of Guns: Firearms a Key Feature of the Hemingway Narrative and Persona

the little woman's fingers wear out" (Selected 330). Appointing himself as the ultimate authority on guns now poses a dilemma for the writer on how much detail to include in his fiction to avoid demanding too much reader knowledge on the technical aspects of firearms. In various passages of his fiction, Hemingway occasionally trips readers, who lack interest in weaponry, with subtle gun details as they seek the deeper meaning of the story.

A technically troublesome scene for readers appears in "The Last Good Country" where the fugitive Nick with his sister Littless carry two types of ammunition for their rifle, and the narrative provides only some information on the power differential of the two cartridges:

They were going after partridges so he pulled out the tube of the magazine and poured the long-rifle cartridges into his hand and then put them into a chamois pouch and filled the magazine with .22 shorts. They made less noise and would not tear the meat up if he could not get head shots. (Complete 539)

Before arriving back at camp, Nick exchanges the cartridges again: "As soon as he was out of sight of his sister he changed the .22 shorts in the rifle for the long-rifles. I won't kill him, he thought, but anyway it's the right thing to do" (542). As Nick moves ahead of his sister, he seems to expect unwanted visitors at the camp. In this scene, confusion could arise over terminology of shorts versus long-rifles, and readers may erroneously think length of guns rather than the inherent power of the two types of cartridges. Littless has accompanied Nick to dissuade him from murdering the game wardens or the Evans boy, and several times she has broached the topic in an effort to calm Nick's potentially murderous intent: "But we're not going to kill people, Nickie. Will you promise me?" (507). Nick dismisses the conversation, but later offers an ambiguous promise with the word "true" (543). Despite Nick's thoughts that he won't kill him, does his action of swapping the cartridges out-ofsight of his sister indicate homicidal intentions? The .22 caliber long-rifle cartridges are more lethal since they are super-sonic, fire a heavier bullet, and would tear the meat up. Had Littless seen the cartridge exchange, she would become anxious and fear that Nick may intend to kill the pesky Evans boy or the wardens. Donald A. Daiker points out: "The detail of Nick's murderous plan suggests that it is more than a passing fancy" (32). Later he gets Littless to stop talking about killing, and Nick reveals that he has been mulling over the dark crime in his head and resolves not to "think about it in front her because she can feel it" (Selected 543). Since the story takes place in wild country, Nick harbored concerns about a bear raiding their camp but did not feel the need to make the rifle more lethal, although the small rifle-even loaded with long rifle cartridges—offers little protection against an attacking bear.

Throughout the Spanish Civil War novel For Whom the Bell Tolls, Hemingway includes considerable technical information on weaponry, and in one scene the handling of a rifle's firing mechanism plays an intrinsic role in the action by nearly leading to the death of Robert Jordan's guide Anselmo in a friendly-fire incident. When Jordan and Anselmo approach the partisan camp of Pablo, they are challenged by a guard who can be heard preparing his rifle to fire. Facing a precarious situation, they try to explain their intentions, but it all takes a humorous turn as no one can remember the identification password. Tension returns to the encounter when Anselmo requests that the sentry Agustìn make his rifle safe:

"Uncock thy piece."

"It is uncocked," the man said in the dark. "I let it down with my thumb and forefinger."

"Thou wilt do that with a Mauser sometime which has no knurl on the bolt and it will fire."

"This is a Mauser," the man said. "But I have a grip of thumb and forefinger beyond description. Always I let it down that way."

"Where is the rifle pointed?" asked Anselmo into the dark.

"At thee," the man said, "all the time that I descended the bolt." (49)

American Research Journal of English and Literature

Page 2 
During this manipulation of the rifle, if the firing mechanism slips from between the rifleman's fingers, the gun will discharge, and Anselmo will die by the actions of a friend. However, besides heightening tension, the dangerous handling of the rifle further establishes that the partisan band employs unorthodox methods of which Anselmo refers to as "guerilla discipline" (49). But in this scene, the handling of the rifle's mechanism borders on the technically impossible. As Anselmo correctly points out, the ubiquitous turn-bolt Mauser rifle design eliminated the knurled bolt that provided positive grip that had long been standard on rifles. Hemingway would have been very aware of its absence on the German-made Mauser rifles as it was so common on American rifles of the era including his own beloved Springfield hunting rifle based on the U.S. military Model 1903. The absence of the knurled-grip surface on the Mauser rifle, makes Agustìn's actions impossible for two other reasons: first, as the Mauser firing mechanism moves forward, it slides inside the outer bolt housing making the claim of a grip of thumb and forefinger beyond description of no benefit since there is nothing to grip as it slides inside the housing; secondly, to prevent corrosion, the metal surfaces of guns are covered in a slippery film of oil. Hemingway would have been cognizant of the impossibility of this dangerous manipulation, and Agustìn-in all likelihood—has quietly engaged the safety lock and tough-guy teases Anselmo into believing that he was in harm's way. Not missing the chance to share a crudity, Agustìn uses the handling of the rifle for the opportunity to throw a sexual reference at the old man with the talk of cock and uncocking and thumb and forefinger. Later, the old man confirms the sentry's jocular nature: "Agustìn is a very good man," Anselmo said. "He speaks very filthily and always in jokes ..." (51). During the dangerous encounter, both Jordan and Anselmo stand unflinching and demonstrate their stalwart natures.

But more is required of the Hemingway hero than standing stalwart in the face of doom-a wide-ranging knowledge on weaponry and military tactics are essential as shown when Robert Jordan's curiosity is piqued when hearing that Pablo's band possesses a machine gun that the gypsy says has "a very rare name" (30). Upon further inquiry, Jordan establishes that it is a Lewis gun because it does not receive ammunition from a continuous belt or a box magazine but rather "from round iron cans on the top of the gun" (30). Subsequently, Jordan demonstrates further military acumen when recognizing that the machine gun has been deployed poorly in defense of the camp and explains to Agustìn how to maximize the weapon's potential:

"You see? From there it was useless," he said. "Look. Those rocks which should protect your flanks give cover to those who will attack you. With such a gun you must seek a flatness over which to fire. Also you must take them sideways. See? Look now. All that is dominated." (294)

Likewise, when Jordon confronts the loss of his electric blasting machine and detonators through the machinations of the drunken and unpredictable Pablo, he quickly engineers a make shift means of rigging hand grenades to set off the dynamite charges (472). Although the detonation of the bridge explosives was successful and belies Pablo's efforts to thwart Jordan's demolition work, it results in the death of Anselmo. But Hemingway has now thoroughly rounded out the character of Robert Jordan as Spanish instructor, military tactician, and weapons expert.

Hemingway expresses joy and pleasure when discussing guns and hunting in personal letters to friends and family, but he seems to ignore the long-standing American tradition of indulging favored guns with pet names. Through a careful perusal of the writer's letters from 1917-1961 collected by Carlos Baker as well as reviewing various anecdotes of his cohorts in other sources publically available, it appears that Hemingway avoids bestowing personalized names on weapons-unlike American frontier legend Davy Crockett and his famous, craftsman-made rifle Old Betsy, or James Fenimore Cooper's fictional character Natty Bumppo and his rifle Killdeer. His guns are called by manufacturer names of Colt, Thompson, Springfield, or Winchester; moreover, he usually gives model type, caliber, or gauge designation such as Springfield 30-06, 6.5 Mannlicher, and Model 12 Winchester twelve-gauge. An industrial age of industrial war requires industrial identification. Hemingway acknowledges this industrialization of the modern battlefield in a letter to Bernard Berenson written in March 
A Culture of Guns: Firearms a Key Feature of the Hemingway Narrative and Persona

1953 from the Finca Vigia: "About the business of fighting and bleeding... There is no mystery or romance about it. It is like an industrial accident" (Selected 810). Aside from the nature of contemporary warfare, using manufacturer names and specifications to identify his firearms was an expedient way for Hemingway to keep his arsenal straight in his mind and to his friends. He owned many guns of which forensic firearms sleuths Silvio Calabi, et al. write that Hemingway "bought, borrowed, loaned out and gave away guns throughout his life, and a comprehensive listing of them is impossible" (8). Although he avoids giving particular guns unique names, Hemingway generically applied terms of endearment for firearms especially in reference to the submachine guns used in Islands in the Stream:

In the dinghy the three of them had their raincoats wrapped around the niños. These were Thompson submachine guns in their full-length sheep-wool cases.... It was because the guns nestled in their sheep-lined cradles, and because the cradles swung when they were strapped open inside the branch of the flying bridge that the Basques had nicknamed them 'little children.' (322-323)

The sweetly-named but deadly submachine guns are identical to a gun the author kept onboard his fishing boat the Pilar, and in a letter to Sara Murphy dated 10 July 1935 from Bimini, Hemingway writes enticingly to his son about killing sharks: "Tell Patrick I have a Thompson Sub Machine gun and we shoot sharks with it. Shot 27 in two weeks. All over ten feet long. As soon as they put their heads out we give them a burst" (Selected 416). The letter further discusses how the Mannlicher rifle failed to stop five sharks destroying a huge tuna they had hooked. This shark battle provides the autobiographical meat used in Islands in the Stream when Thomas Hudson's son David is saved by a burst from a Thompson gun after the .256 caliber Mannlicher fails to stop a shark chasing the swimming boy:

He had the 256 and shot just ahead of the fin. The shot was over and threw a spurt of water ... Thomas Hudson was trying to stay loose but steady, trying to hold his breath and not to think of anything but the shot; ... he heard the submachine gun start firing from the stern ... the biggest hammerhead he had ever seen rose white-bellied out of the sea ... Eddy's gun rapping and ripping into the white of his belly.... (79-80)

In this scene, the Thompson effectively stops the shark, but when Hemingway first acquired the gun in Bimini, it offered less than stellar performance and apparently caused more problems than it solved as related by Baker:

The tommy-gun soon helped to produce a rift between Ernest and Mike Stater.... Fishing with Ernest ... he hooked a 12-foot marlin. After an hour's fight, he had it moving towards the Pilar when the sharks came zeroing in. Ernest began plugging them with bursts from his tommygun on the pretext that he had to defend Mike's marlin from being mutilated. The effect was the reverse. The water turned pink with blood... Ernest had helped to destroy the biggest marlin Mike had ever hooked. (272-273)

Apparently, Hemingway mistakenly bought into the hype of sensationalized newspaper stories of the era about the menacing Thompson submachine gun in the hands of gangsters robbing banks and held a disproportionate view of the power of the gun-it was a submachine gun, reduced from full-military power by design, and only fired a pistol cartridge; very effective on close-range soft-skinned humans not hiding behind anything unlike a tough-skinned shark attacking through water.

But Hemingway demonstrates true understanding of the Thompson gun in To Have and Have Not when Harry Morgan battles the murderous Cuban revolutionaries. It is the fight parameter for which the Thompson gun was designed-massive fire power up close and personal. Harry has the right tool for the bloody task because the Thompson is an ambidextrous weapon-easily fired by right or left-handed shooters and by the disabled Harry 
A Culture of Guns: Firearms a Key Feature of the Hemingway Narrative and Persona

with his prosthesis hook. Hemingway details thoroughly the manner that Harry stows the Thompson for quick and surreptitious access in the engine compartment of the boat: "Kneeling between the two engines he reached up to take the gun. There were only two movements to make.... He tried it and it came easily one-handed" (143). The technical accuracy of rigging the sling and the subsequent tactical moves made during the gunfight suggest that Hemingway may have performed a dry-rehearsal of the necessary steps onboard the Pilar with his own Thompson submachine gun. In an earlier scene, Harry's wife reluctantly brings the Thompson and inquires if he wants any boxes of shells, but the one-armed Harry replies: "No. I can't load any clips. I got four clips" (127). Hemingway missed this aspect of loading the Thompson-clips are easily loaded one-handed by pinching the clip "tight between his thighs" in the manner that Harry stabilized his wounded arm on the earlier rum-running trip gone bad (77). Ultimately, Harry's ammunition logistics were correct in that he only used two of the four loaded clips carried in anticipation of another "bad trip" (127).

Along with the Thompson submachine guns referenced with disarmingly cute names in Islands, Hemingway refers to the Model 12 Winchester in the novel Under Kilimanjaro with the alternative name Sten gun because the safari crew "all believed it was an automatic weapon since it could be fired faster than any automatic shotgun ... It takes twenty thousand cartridges to break in a pump gun so that it handles quicker than your eye can follow..." (391). Calling the Model 12 shotgun a Sten gun is an image misnomer as the Sten submachine gun was made in Britain during the Second World War when labor and materials were scare, produced quickly and cheaply from stamped sheet metal, fired a pistol bullet, and is as awkward looking as junk under a plumber's workbench-not a finely-machined sporting shotgun manufactured by one of America's premier gun makers. And despite his long familiarity with the Model 12, Hemingway attributes its rapid rate of fire to the gun being well broken in but fails to mention the design feature permitting the high-rate of fire-its trigger mechanism. The Model 12 uses no interrupter in the trigger included by many gunmakers as a safety feature to prevent the gun from firing if someone foolishly closes the pump-action on a live shell with finger on the trigger. On shotguns without trigger interrupters, the shooter can hold the trigger back and pump the action to imitate automatic fire-a feature that was appreciated by soldiers armed with trench shotguns in the First World War, and used by Hemingway to instill the idea into the Africans that it was a witchcraft gun.

Curiously, two central firearms of Hemingway's African safaris suffer under-identification: the Westley Richards .470 caliber of the 1933 and 1934 hunt, and the Westley Richards .577 of the 1953 and 1954 hunt which are the powerful English-made Nitro-Express double-rifles. Emulating Theodore Roosevelt in African Game Trails, Hemingway writes constantly about his American Winchester and Springfield guns but uncharacteristically does not use the manufacturer name for the big English guns. Unlike the Springfield, the Nitro Express doublerifles were the true African dangerous-game weapons on the expeditions with their enormous stopping power and feature in nearly every hunting scene as the go-to rifle in dicey situations-but Hemingway always refers to them by caliber designation or as the big gun, the heavy gun, or the double rifle. Did Hemingway harbor a latent patriotism for American gun makers and a xenophobic bias against the British that kept him from using the name of the English gun firm Westley Richards? In a 1930 letter written to Archibald Mac Leish, Hemingway takes issue with British attitudes on proper equipment for hunting Africa: "You see, the thing is that the English have a certain way about guns, and they high tone us always so that the majority of big game hunters get buffaloed by them" (Selected 330). On both Africa safaris featured in The Green Hills of Africa and Under Kilimanjaro, Hemingway snubs the English by not addressing with proper titles the Westley Richards Nitro Express rifles, but the potent sporting armament of the Empire was the only reliable way to stop a crushing demise from rhino or buffalo- the lighter caliber American Springfield could not match up to that high-tone mark. Other Europeans fare better recognition, and the Austrian-made $6.5 \mathrm{~mm}$ rifle is consistently called "Mannlicher."

While shooting the .470 double rifle in The Green Hills of Africa, Hemingway displays fundamentally bad marksmanship skills: "the big gun feeling heavy and unfamiliar, held on the buff's shoulder, squeezed off and flinched without firing" (69). The passage explains that the trigger felt like "metal stuck against metal" and was

American Research Journal of English and Literature

Page 5 
nothing like the trigger on his Springfield with its "sweet clean pull." The holy tenets of accurate shooting center on knowing thy weapon, maintaining thy point of aim, and manipulating thy trigger correctly. In this escapade, Hemingway has probably violated all three of the tenets. Unfamiliarity caused him to leave the safety engagedmetal stuck against metal - which prevented the gun from firing and revealed the flinch, although he realized his omission and released the safety lock because he eventually got the rifle to fire. The flinch occurred because he anticipated the discharge by knowing the exact microsecond the gun would fire by jerking the trigger that causes the reflex action of tightening the shoulder in anticipation of the loud explosion and painful recoil-it throws the rifle off the aiming point and causes the bullet to strike wide of the mark. It happens so quickly that it cannot be seen unless the gun fails to fire. Avoiding the flinch remains a challenge for all shooters and requires a Zen-like mental conditioning to control the body when an extremely powerful explosion detonates in the firing chamber inches from the face, causing violent recoil that may break the body as Hemingway feared would happen if he fired the even more powerful .577 in the "prone" position (Kilimanjaro 321). Hemingway does narrate the concept of the Zen-moment of shooting while hunting rhino: "I was watching, freezing myself deliberately inside, stopping the excitement as you close a valve, going into that impersonal state you shoot from" (Green Hills 53).

Understanding a shooting concept and applying it during the excitement of the hunt can be a challenge, and Hemingway recognizes that rifle and shotgun require different techniques which he writes about in a hunt in Montana in 1930: "I saw a big bull elk at sixty yards it was so easy I just shot it at him like a shotgun. But that isn't what you do in rifle shooting ... There's only one bullet, and it goes wherever you point the gun ..." (Selected 330). Hemingway's years of being a top-flight bird hunter offered significant skills challenge when he transitioned to high-powered rifles. Safari guide Philip Percival's gentle condemnation recognizes Hemingway's poor rifle skills when he fired badly on Grant's gazelles: "everyone misses when they first come out here" (Green Hills 206). The bottom line clearly revealed during the African safaris was that Hemingway was a good wing shot but a mediocre high-powered rifle shot, armed with the bad habit of a flinch, and burdened with poor eyesight. No hunter in American letters-except for the myopic Theodore Roosevelt-would have benefitted more from the use of a telescopic sight; moreover, the writer's Springfield was fitted with a well-designed mount for quickly installing a scope. In the age of Roosevelt and the time of Hemingway's 1933 safari, telescopic sights had not yet come of age and offered poor optical resolution and field of view. But by the 1953 safari, refinements in the sights offered huge advantages to those with weak eyes. But Hemingway remained critical of telescopes as a crutch for a new-generation of hunters: "Now no clients would shoot anything without a telescopic sight. It was considered as necessary as a pink coat in the hunting field ..." (Kilimanjaro 276). Moreover, in talks around the campfire, Hemingway digested Percival's critical views of shooting range practice as preparation for dangerous game: "He disliked and distrusted the target-range... 'Never miss until they have to shoot a really good kudu at twenty yards'” (48). No doubt Percival is speaking from first-hand experience, but go tell military-trained snipers, who shoot the most dangerous game in the world, that practice on the rifle range offers little value. Although Hemingway enjoyed pigeon shooting on professional ranges, but similar to Percival, he had a disdain for the rifle range, perhaps, for its ego-humbling paper target that reveals in strong black and white detail the ability of the shooter. Out in the field, when shooters miss their marks, the puff of dust from the bullet strikes do not reveal how badly the shots went astray by inches or yards. On the target range or in the field, executing consistent successful shots on the black bull requires masterful skill.

Adjectives used by Hemingway when describing firearms run the gamut of romantic terminology, but deeper issues churn in the nether regions and his sexual psyche. Hemingway's endearment with firearms enters a mysterious realm of eroticism, sexual fetish, and divergent symbolism of procreation. In A Farewell to Arms, Frederic Henry describes a war trophy: "My Austrian sniper's rifle with its blued octagon barrel and the lovely dark walnut, cheek-fitted schutzen stock ... hung over the two beds. The telescope that fitted it was ... locked in the trunk" (11). Key features of this scene reside with the proximity of beds, the adjective lovely, and the location 
A Culture of Guns: Firearms a Key Feature of the Hemingway Narrative and Persona

of the telescope. The association of firearms with beds resonates through a number of Hemingway works, and ostensibly the reader would sense that the weapons must be kept close at hand to repel attack: "So I lay in the cot with the old shotgun rigidly comfortable by my side and the pistol that was my best friend ..." (Kilimanjaro 381). Keeping a firearm in bed is a tactically poor technique as entanglement with bed linen prevents quick deployment and exposes the weapon to rust-inducing perspiration. For quick access, weapons are kept beside or at the head of a bed. Despite Hemingway calling them comfortable, hard metal weapons are anything but in this intimate environment. The guns going to bed with Hemingway and his characters are not to repel violent attack but rather to offer emotional comfort and erotic fantasy. Only Robert Jordan sleeping in a snowstorm has cause to keep his pistol out of the weather inside his bedroll, which he uses to fire on an enemy cavalryman (Bell 287). The other sleep gun to see action occurs in Islands in the Stream where Thomas Hudson seeks a place to nap and uses the .357 magnum pistol to destroy a menacing crab, but Hudson promises that it will "kill something better than land crabs when the time comes" (292). The following scene shows that the better target is Hudson himself in a dream: "he moistened the .357 Magnum and slipped it easily and sound asleep where it should be" (297). The fetishized pistol would be the Smith and Wesson Model 27, and fortunately for Hudson the sodomy takes place in a dream since the pistol features a prominent and sharp-edged front sight which would cause grievous injury if inserted into anything but a dream orifice.

In the opening scene of Farewell, Henry describes the soldiers marching on the road: "under their capes ... gray leather boxes heavy with the ... long $6.5 \mathrm{~mm}$. cartridges, bulged forward ... marched as though they were six months gone with child" (4). The bulge forward from the belts, the long slender cartridges with seed-like bullets enclosed in leather and wrapped in cape create an impossible sterile image of procreation and presages the stillbirth of Henry's son at close of the novel. Like the cartridges ensconced within leather boxes, a key component of Henry's sniper rifle is the telescope, long and phallic-like, also enclosed within a trunk. The trunk, cartridge boxes, gun cases, and holsters-become female repositories of the male phallus represented by the guns and components within. The pistols slide into the well-oiled holsters; the Thompson and the Mannlicher (strongly male names) onboard the Pilar slide into soft "sheepskin cases ... well-impregnated with the Fiendoil" and likened to "cradles" (Islands 77, 322). Again, Hemingway creates image in opposition with instruments of death swaddled and called niños.

In Under Kilimanjaro, the Wakamba girl Debba becomes enthralled with the pistol holster in several scenes $(34,336,351)$. Hemingway discovers that Debba's constant rubbing and pressing of the holster arises out of fascination with its embossed flower: "she would sit very straight and press her thigh hard against the holster ... she wanted, then, was to impress the carving of the holster into her thigh" (34). Flower blossoms have long represented female genitalia in many cultures, but what does Hemingway strive to create in these scenes? As the female holster encompasses the male pistol and the embossed flower establishes further female imagery, does Debba's rubbing of the holster and pressing of the flower show homosexual intent, or simply the desire of a young girl to have a raised tattoo? But for Hemingway the pistol remains an artifact of sexual symbolism as revealed by Richard Cantwell in Across the River and into the Trees: "We call a pistol slapper a non-fighting man, disguised in uniform, or you might even call it costume, who gets an erection every time the weapon slaps against his thighs" (218). For Cantwell the pistol slapper represents an ineffectual "non-fighting man" armed with an equally ineffectual pistol/phallus that is part of a dissembler's costume. Richard Fantina states: "Rather than exalting the male phallus, Hemingway's work consistently seeks to dethrone it" (97). Not only is the phallus dethroned, but Hemingway's narrators often find it incarcerated within the encompassing folds of female imagery. Incorporating guns and their accouterments in these scenes, Hemingway transposes the tools of hunting and warfare deep into the world of sexual fantasy and eroticism while creating powerful symbols of divergent but sterile procreation.

Hemingway's love for firearms is evident even while on the receiving end of high-velocity projectiles, and he avoids the disparagement of firearms by framing the discussion of his First World War wounding in joyful 
A Culture of Guns: Firearms a Key Feature of the Hemingway Narrative and Persona

terms. Concussed by a heavy mortar round, ripped by shrapnel, and bedded in convalescent pain in an Italian hospital, Hemingway writes a letter to his family dated 18 August 1918 that lists the different types of ordnance fired in his direction:

Well I can now hold up my hand and say l've been shelled by high explosive, shrapnel and gas. Shot at by trench mortars, snipers, and machine guns, and as an added attraction an aeroplane machine gunning the lines. I've never had a hand grenade thrown at me, but a rifle grenade struck rather close. Maybe I'll get a hand grenade later. (Selected 14)

Written with tone of a carnival spiel stemming from the phrase added attraction, the letter reads like the words of a proud and happy boy scout writing from camp listing merit badges earned and eagerly looking forward to the Eagle Scout badge of the hand grenade. The young Hemingway masks the pain and terror of his wounding with an assumed bravado to avoid creating unnecessary concern with his parents, but one would expect a few derogatory adjectives directed at the weaponry that may have crippled him for the rest of his life. On one occasion, Hemingway does curse his favorite rifle: "I was shoving shells down into the damned-to-hell lousy, staggered, Spring field magazine ..." (Green Hills 178). The staggered magazine (cartridges positioned nearly side-by side in the magazine well) is one of the features that makes the rifle an excellent sporting weaponthere is no obtrusive magazine protruding from the bottom of the rifle and permits a slim design and swift handling. Other than the excitement of the moment, it is unclear why Hemingway struggles with reloading as the simple-to-recharge magazine was designed for soldiers caught in the frenzy of battle. The Springfield only becomes more difficult to load if a telescopic sight is installed which partially blocks access to the magazine and requires more juggling to get cartridges into position. As mentioned above, Hemingway eschewed scopes even though he wanted to "kill cleanly" (101).

Guns as gifts reveals another area of Hemingway's association of pleasure with firearms, and he makes a special request in the postscript of a letter to his war buddy Colonel Charles "Buck" Lanham during the closing days of World War II in Europe: "Now you are over-running Krauts could [you] possibly get me 2 P38s for the Kids?" (Selected 581). This is not a request for a couple of pop guns but rather for the most advanced high-capacity German military pistol of the time, incorporating features still used on many current military handguns. Discussing his fiftieth birthday party in a letter to Charles Scribner in 1949, Hemingway talks of the "wonderful" gifts that he received with "a .22 Cal Colt Match Target pistol" at the top of the list that was "smuggled" into Cuba by Juan Dunabeitia (659). Ammunition also makes the grade for proper gifting as Hemingway writes in July 1939 to Hadley Mowrer: "Much love and love to Bumby. I will bring him a lot of ammunition for his rifle from the case that is at Key West. Ask him if I should order some pistol cartridges too" (490). Other letters prattle on about wonderful times hunting with wives, friends, sons, and the numbers of innocent animals killed but are too numerous to analyze within the confines of this paper and become redundant. However, from the correspondence, another aspect of Hemingway's relationship with guns arises-using firearms as the measure of man.

While hosting film star Gary Cooper in Sun Valley, Idaho in 1940, Hemingway penned a letter to his editor, Max Perkins, and assessed Cooper by way of comparative shooting skills: "Cooper is a very, very fine rifle shot and a good wing shot. I can shoot a little better than he can with a shotgun but not nearly as good with a rifle ..." (518). Another of Hemingway's friends, from the last decade of his life, would come under the measuring stick of shooting-skills in a letter written in 1960 to Nathan Davis: "Hotch [A. E. Hotchner] shot well on targets but disasterously [sic] in the field on his last day and felt very badly. I felt worse as I thought he had really learned to shoot" (Selected 898). Besides sizing up friends, Hemingway also sizes up family members vis-a-vis hunting and shooting activities incorporated into his parenting style.

Father Clarence Hemingway bonded with son Ernest through the activities of hunting and fishing, a trait that Ernest perpetuates into the next generation as a means to bond with his sons and as a touchstone to assess

American Research Journal of English and Literature

Page 8 
A Culture of Guns: Firearms a Key Feature of the Hemingway Narrative and Persona

character development. In another letter to Hadley Mowrer on 23 July 1942, he writes mostly about his son Gregory: "Gigi is fine this summer. He is a better boy all the time. He is shooting marvellously and so is Patrick" (536). The pleasant times shooting with his own father and his sons would provide the stimulus for Hemingway to meld the experiences into the short stories "Father and Sons", "I Guess Everything Reminds You of Something", and the novel Islands in the Stream with son Gregory providing provocative material for the latter two. But Hemingway's relationship with his youngest moved into tempestuous straits. Robert C. Clark recognizes that he "spent comparatively little 'quality time' with his third son, but Hemingway felt that they shared a mutual understanding. His 'connection' with Gregory seems to have been based on his belief that they both possessed a 'dark side.' They saw it in one another, according to Hemingway" (95). The lack of quality time with son Gregory follows the pattern established by father Clarence when he stopped hunting with young Ernest. James Hughes Meredith analyzes the consequences of father Clarence's actions: "By shutting out his son, Hemingway's father ended hunting as a nurturing, father-and-son experience, and Ernest could not help but link the shotgun with his father's withdrawal, an experience which must have created immense emotional confusion within the young boy" (189). The story "I Guess Everything Reminds You of Something" closes with the harsh indictment from a disillusioned parent: "Now he knew that boy had never been any good. He had thought so often looking back on things. And it was sad to know that shooting did not mean a thing" (Complete 601). During the composition of that coda, perhaps Hemingway caught his own reflection in a mirror and assessed how shooting sports had not ameliorated his own dark side.

Not only does Hemingway measure men by referencing firearms but also women. Writing to Harvey Breit in July of 1956, Hemingway discusses his courtship to Mary Welsh and an army general in competition for Miss Mary who instructs her on pistol craft: "He taught her to shoot a .45 colt issue pistol and naturally no woman can hit anything with that peculiar device" (Selected 862). Hemingway demonstrates more superior-male sexist attitude towards women in shooting sports when writing to Charles Lanham about nearly being killed in a hunting accident in 1946: "As you know women should never be entrusted with automatic weapons and Mrs. Howard (Slim) Hawks proved this again when we were unloading guns to get into the car and she let her 16 gauge Browning automatic off so close to my head that it (literally) singed the hair at base of skull" (613). Hemingway goes on to discuss how he downplayed the dangerous action as well as acquiring the beautifully made gun that nearly killed him.

Sexist attitudes are not the only less than admirable sentiments expressed in Hemingway correspondence collocated with shooting. In a 1936 letter with racist content to Ivan Kashkin, Hemingway reminisces about drinking with Russian humorists Elias Ilf and Eugene Petrov in New York a few months prior. The two humorists were on tour of the United States and the ever hospitable Hemingway extended them a special invitation: "We asked them to come down to Key West but their itinerary only took in Florida as far south as Jacksonville. I promised to let them shoot a nigger or to shoot a nigger for them if they had moral scruples and one of them asked if we would have the nigger roasted so he evidently didn't take the offer seriously. Or is he maybe a cannibal" (Selected 430). The bulk of the letter incorporates a number of satirical inclusions that target mouthwash commercials sponsoring a "Death house" radio program as well as a tale of tooth extraction as essential for marriage in Switzerland showing Hemingway lampooning cultural traditions-but suggesting the morally repugnant and murderous activity of shooting black people and roasting them goes far beyond the pale of acceptable satire.

Apart from assessing his familiars, Hemingway uses shooting to gauge personal health. In an exuberant letter to Mary Welsh in April 1945, Hemingway writes: "Woke up in the morning feeling wonderful and decided would shoot to see how the reflexes were comeing [sic] on. Shot fast and very secure ... Three weeks ago anybody seeing me shoot pigeons would give you odds I'd never, never come back. And yesterday was faster than steel trap" (Selected 587-588). The writer's concern over his reflexes stems from the serious concussions he 
A Culture of Guns: Firearms a Key Feature of the Hemingway Narrative and Persona

received in the later stages of the Second World War in Europe that caused severe headaches and balance issues for a long time. Dr. Andrew Farah observes that on top of the nasty concussion he received in the traffic accident in London, Hemingway was blown off a motorcycle by a tank round and "likely suffered two successive concussions-one blast and a second on impact" (33). Being able to shoot quickly and accurately on pigeons suggested to the author that he was recovering from the horrific medical ordeal of brain trauma.

Other family members employed shooting as a health barometer as well. When son Gregory discussed Hemingway's antics at his sixtieth birthday party with biographer Jeffrey Meyers, it was with concern in that he "had always been taught to treat guns with the greatest care and caution, knew his father was deteriorating when he read that Hemingway took uncharacteristic risks and shot cigarettes out of Ordóñez's mouth" (529). This dangerous showing off by hazarding the bullfighter contradicts what A. E. Hotchner observes during pheasant hunting in Idaho, and that the Hemingway of more lucid days "had a few strict rules: guns in the car must never be loaded; guns being carried through or over fences must be broken at the breech" (192).

Notwithstanding the strict rules about gun safety around fences and automobiles observed by Hotchner, how perilous was it to be in the field or on the range with Hemingway the drinking, accident-prone risk taker armed with powerful weaponry? He lived many decades without killing associates during outdoor activities, but occasions arose when firearms safety officers would grit their teeth and head for cover while police officers would arrest and file charges. Hemingway recognized that cars present clear and present danger for hunters, when leaving and returning from the hunt, such as the Mrs. Howard Hawkes episode related above; but an earlier incident occurs in The Green Hills of Africa when a rifle discharges when handled carelessly and is recorded in Pauline's journal: "there was a terrific gun report beside Ernest's head and I thought he was killed. After shooting the zebras he had put the gun uncocked on top of the car and it fell off stock first on the ground beside the car and went off" (209). The rifle that fired is not identified, but in all likelihood, it was the Springfield as Hemingway had been shooting zebras and that was his gun of choice on less-dangerous game. But rifle type does not matter as any loaded gun sliding off a car and hitting the ground can discharge, but a telling clue is Pauline's reference to the gun being uncocked. Hemingway consistently mishandled the Springfield rifle by using the archaic cocking knob to lower the firing bolt over a live cartridge in the misdirected effort to put the gun into a safe mode as Agustín claims he had executed with the Mauser in For Whom the Bell Tolls (49). Without engaging the safety lock or unloading, the Springfield would only need a minor bump to the knurled knob to push the firing pin into the cartridge, or be dropped on the stock to cause the firing pin to rebound off its spring and strike the cartridge and cause it to fire. When Hemingway discovers in The Green Hills of Africa that M'Cola had the Springfield cocked behind his back, it made him "black angry" (55), forgetting, in the excitement of the hunt (53), that he probably handed it to the gun bearer cocked—but failed to engage the safety. The loaded gun cocked or uncocked still presents serious danger, and three passages in Under Kilimanjaro offer in-depth description of Hemingway using this dangerous-mode while handling the Springfield rifle $(68,173,295) .{ }^{1}$ Another major point of gun-safety prohibits leaning or placing guns on vehicles since they rock back-and-forth on their springs and car surfaces are slippery. Guns will slip and fire. As per the Hawks' accidental discharge, safety demands close supervision of inexperienced shooters or those using an unfamiliar firearm. Male chauvinism and zebra karma aside, Hemingway's carelessness set the stage for the incidents that nearly drove bullets through his head-but the African incident did have a plus-side as it drove into his skull the partial inspiration for a story. In the Introduction to the 2015 edition of The Green Hills of Africa, Sean Hemingway discusses the near death of his grandfather and relates: "this real life scenario sparked the idea for the accidental shooting in the Hemingway story "The Short and Happy Life of Francis Macomber" (XVI). Eclipsing Sean's insight into the seminal origins of the work, Meyers details the death of safari client in 1908 that was mentioned to Hemingway by his guide Philip Percival that offers detailed precedent for the story (268).

Mixing gunpowder and alcohol has sent many to hospital or prison, and Hemingway was able to avoid the latter and even champions the concept that drinking and shooting are necessary in a letter to Ivan Kashkin in August

American Research Journal of English and Literature

Page 10 
A Culture of Guns: Firearms a Key Feature of the Hemingway Narrative and Persona

1935: "it always helps my shooting" (Selected 420). Meyers chronicles the writer in a black rage that gave Mary Welsh pause for concern over the mercurial anger of her future husband in a hotel in Paris "when he placed a photograph of her Australian husband in the toilet bowl, blasted it with a machine pistol and flooded their room at the Ritz" (416). In all likelihood, the pistol was charged with full-jacketed military ammunition, which easily perforates wooden walls as well as ricochets when striking hard surfaces like a porcelain toilet. They were lucky not to be struck by bullets bouncing back or arrested for endangering or killing people in adjacent rooms. Paris wartime conditions and understanding hotel staff apparently kept Hemingway out of jail, but the incident demonstrates a horrible lack of common sense. It is unclear whether killing the innocent toilet and the Aussie photo involved alcohol or not, but an earlier pistol shooting event probably did as Hemingway was fishing with his cronies. On board the Pilar in April of 1935, Hemingway "with the gaff in his left hand and his Colt pistol in his right, he held the shark in position and began pumping bullets into its head. Suddenly the gaff broke with a loud crack and Ernest saw that his legs were covered with blood. He had managed to shoot himself in both legs at the moment the gaff broke" (Baker Life 271). It remains a miracle that no one was killed by the act of juggling a fighting shark in one hand and firing an automatic pistol in the other while balancing on the heaving deck of a boat. The lack of sound judgment here astounds and smacks of the famous last words of many who partake of the gunpowder cocktail: "Hold my drink and watch this."

Hemingway's father Dr. Clarence was the principal person involved in his son's hunting and shooting education, and sister Carol recollects: "So much has been written about his use of guns. They were just another tool that he took good care of and used expertly as he did with an ax or a scalpel" (Gardner 26). Emulating his father's care of tools, Ernest becomes enraged when he notices that his gunbearer failed to clean the Springfield rifle and silently chastises him for his omission: "M'Cola had seen the rusty bore. His face had not changed and I had said nothing but I was full of contempt and there had been indictment, evidence, and condemnation without a word being spoken" (Green Hills 140). At some point, most children undergo parental wrath for failing to take care of items entrusted to their care: did young Ernest suffer such an inquisition under Dr. Clarence for failing to take care of a rifle or shotgun entrusted to him? Carlos Baker notes: "The doctor's ideas of right and wrong were firm and fixed. Any offenses were likely to rouse him to instantaneous indignation" (Life 31). Younger brother Leicester relates an incident where Dr. Clarence directs sarcastic indignation at him on the proper care of firearms when discovering that a .22 rifle that Ernest has traded to him has interior damage to the barrel: "Look at this ... This is the gun I taught Ernest to take care of properly. He let something get into the bore and then tried to shoot it out ... it will have to be completely rebored. Medals for military valor, but he ruins a good weapon like this" (My Brother 75). Fortunately for Ernest, he was now a married adult and no longer subject to paternal wrath. But as the earlier incident with the rusty Springfield shows, Hemingway took gun care very seriously as well, and he devotes several paragraphs in Islands in the Stream on the .256 Mannlicher-Shoenauer carbine and preventing gun rust in a marine environment:

It was really too good a gun to keep on a boat but Thomas Hudson was so fond of it and it reminded him of so many things so many people, and so many places that he liked to have it with him and he had found that, in the sheepskin case, once the clipped wool was well impregnated with the Fiend-oil, the rifle was not harmed at all by the salt air. (76-77)

Like his father, Hemingway embraced firearms as efficient tools for hunting as well as recognized their central role in modern warfare-but he extended them into the greater realm of potential problem solvers for political, personal, and social conundrums. Writing a biting political comment on left-leaning activists to Paul Romaine in 1932, Hemingway states: "Would as soon machine gun left, right, or center any political bastards who do not work for a living..." (Selected 363). When aligning himself with the downtrodden classes, Hemingway writes on 5 February 1937 to Harry Sylvester that his "sympathies are always for exploited working people against absentee landlords even if I drink around with the landlords and shoot pigeons with them. I would as soon 
A Culture of Guns: Firearms a Key Feature of the Hemingway Narrative and Persona

shoot them as the pigeons" (456). In a letter written in 1935 to John Dos Passos, Hemingway vents his anger at the New Republic and antagonistic critics and states that he "would like to take the tommy gun and open up at 21 or in the N. R. offices or any place you name and give shitdom a few new martyrs ..." (427).

Eliminating political and career irritations by gun violence suggested in his hyperbolic bombast, Hemingway moves on to domestic targets. Feeling the wrath of scorned wives, he writes to Max Perkins in 1943 on how to deal with personal relationship problems: "If you leave a woman, though, you probably ought to shoot her. It would save enough trouble in the end even if they hanged you" (554). However, as cynical as the letter reads, the author makes it clear that his marital problems were entirely of his own creation. When Ezra Pound reaches new levels of mental instability in 1943, in a letter to Archibald Mac Leish, Hemingway adroitly states: "If Ezra had any sense he should shoot himself" (545). Hemingway seems to view gun violence as the proper treatment for life's many ills. Besides shooting ex-wives and former friends, Hemingway comes up with a rather bizarre use for firearms. Relating an anecdote about staying at the home of Nanyuki Franchetti in Italy to Charles Scribner, Hemingway writes how he and wife Mary assisted with the disposal of some unwanted decorations: "we had some very interesting statue shooting with elephant guns after lunch. I had never shot statues before and was a little reluctant to cut loose at them with a 477 but Nanyuki's mother suggested the shoot, as she said she was sick of these particular statues ..." (685). When receiving this letter in 1950, perhaps editor Charles Scribner thought that another premier author of the publishing house was heading for a crack-up like the late F. Scott Fitzgerald.

Earlier, upon hearing that his old friend from his Paris years was suffering family, financial, and medical woes, again Hemingway reaches into the racist bag to pull forth advice. Anticipating the insurance suicide-scam of Arthur Miller's Willy Loman, Hemingway writes Fitzgerald a letter in 1935, during his career low, and counsels tongue-in-cheek on how to deal with his problems: "If you really feel blue enough, get yourself heavily insured and I'll see you can get killed. All you'll have to do is not put your hands up quick enough and some nigger son of a bitch will shoot you and your family will be provided for and you won't have to write anymore..." (428). Outside of the rampant racism, the letter includes excellent humor on the postmortem disposition of Fitzgerald's various organs while prescribing shooting as cure for the beleaguered writer. And in the same vein for ending human misery in To Have and Have Not, Harry Morgan dwells on "those admirable American instruments ... so well-designed to end the American dream when it becomes a nightmare ..." (238). But Hemingway would not follow the advice of Harry on the "native tradition of the Colt or Smith and Wesson" but rather selected the power of a shotgun for his penultimate decision on that day in July of 1961 to render the final solution to a stagnating career and a life spiraling downward into deep decay of mind and body, so unacceptable to a man who had lived bigger than life. In the end, a Nobel prize-winning author incapable of composing a simple suicide note, and-rather than a pen - the cold steel barrels of a shotgun were the last thing he would ever hold in this world. Using the shotgun, there would be no lingering death throes and "hoarse breathing noises" as witnessed by younger brother Leicester when father Clarence selected a small-caliber Smith and Wesson pistol for his suicidal task (Meyers 210).

Perhaps no better way Hemingway expressed his love for hunting and the shooting sports than when he hung a Waldo Pierce painting in a prime location in his Key West home and writes to the artist: "Have your two partridges with shotgun, a damn fine picture, over the fireplace in the dining room" (358). Hemingway, ever the exuberant sports enthusiast, loved to discuss the minutiae on all things in which he was interested. Outside of boring his friends in conversation and in his personal letters, Hemingway did have a relief valve for showing off his extensive knowledge on the tools of the sporting world-magazine articles that reached out to those who hungered for detailed specifics on everything from correct fishing tackle and use to firearms design and function. Baker notes: "Between 1933 and 1936, Hemingway had contributed twenty-five articles, chiefly in 
A Culture of Guns: Firearms a Key Feature of the Hemingway Narrative and Persona

the form of 'letters' on fishing and hunting, to the new men's magazine, Esquire" (Artist 209). With his vast worldwide experience in rugged outdoor sports and his keen knowledge of the necessary peripherals required for a successful expedition, Hemingway, in the mindset of Americans, had morphed into the quintessential hunter and fisherman. In October of 1937 prior to the release of To Have and Have Not, the editors of Time magazine tap into Hemingway's popularity by using a Waldo Pierce painting on the cover, sporting the handsome writer deep-sea fishing. Although the picture focuses on the activity of fishing, the accompanying quote is the last words of Harry Morgan dying of a gunshot wound. For Hemingway, fishing was rarely far removed from shooting. To capture the true essence of Hemingway as sportsman, the editors of Time would have been better served to use an earlier painting by Peirce showing the caricatured antics of Hemingway and cohorts shooting a harpooned shark at point-blank range with an ancient blunderbuss (Voss 28).

\section{CONCLUSION}

In the latter-half of the twentieth century, popular media heroes underwent inversion, with characters brandishing strangely customized guns or using models radically out of place for their respective professions. Western star John Wayne starts the craze rolling with his Winchester carbine featuring an oversized operating lever and becomes his trademark gun through many movies (Stagecoach); television bounty hunter Steve McQueen chops the barrel on his Winchester carbine and converts it into an awkward pistol (Wanted Dead or Alive); and last but not least, Clint Eastwood waves around a grotesquely-oversized magnum handgun, no detective would ever carry, and forces the Smith and Wesson company to put on extra shifts to meet the demand for the most powerful handgun in the world (Dirty Harry). Fans could not get enough of these new hero types where strength flows from gimmicky weapons rather than as an innate feature of character. Hemingway deftly avoids this hero trap and never permits the appearance of a weapon to become the central aspect or dominate a character as seen in the story "The Porter" where George demonstrates razor fighting to young Jimmy and discusses the features of the weapon: "keenness of edge and simplicity of action. Now a greater than these two. Security of manipulation" (Complete 576). George lectures that it is the skill of the user and not the ordinary razor that creates lethality. Marc Dudley brilliantly delves into the story in terms of race relations and comments on George's razor philosophy: "true mastery is found in the manipulation of the instrument, not in the instrument itself. The magician, he assures us, not the wand, holds the power" (41). Hence, the protagonists of Hemingway define their choice of weapon and the weapon does not define the character, although a keen understanding of weaponry and accouterments remains essential.

Despite a few peccadillos in his gun-handling and knowledge-understandable with the plethora of different ammunition types and gun designs - when Hemingway includes firearms in fiction, he provides sufficient technical complexity without slowing narrative momentum or bore those who tender little interest in weapons. Furthermore, it would be easy for readers of Hemingway to dismiss the shotgun "propped against the load of wooden decoys" (1) carried in Richard Cantwell's duck boat as just another hunting tool and not fully realize the depth to which the writer incorporated firearms into his life and fiction-and beyond into the regions of erotic dreams and fantasy. When Hemingway taps the wooden grips of his pistol for luck, what mystical door of superstition is he knocking on? (Kilimanjaro 270). Moreover, Hemingway dovetails the idiom of shooting sports into his language and writes "I'll shoot you a good letter" (71); "shoot me the dope" (79); and "I wish we could shoot you a bottle of absinthe" (Selected 304). Many other examples are extant, and critics researching Hemingway occasionally use the phrasing in their own styles: William E. Coté writes: "provides valuable ammunition..." (89); and Robert Risch: "Hemingway takes some solid shots ... (53). Perhaps, Hemingway's enthusiasm for high-velocity activities and its respective idiom is addictive and surreptitiously infiltrates the psyche of his audience. And although Hemingway nearly wrote the book on a number of aspects of deep-sea fishing, he never internalizes into the culture of his persona his fishing equipment in the manner in which he did with firearms, nor does he create erotic fantasies with his fishing poles. Philip Young analyzes that "no writer can write well about what he has not lived, known and found real for himself" (253). And truly, few writers in

American Research Journal of English and Literature

Page 13 
American letters have immersed themselves more deeply into the ocean of experience than Ernest Hemingway. Notwithstanding the occasional misstep in knowledge and handling, when it came to firearms within his life and narrative, Hemingway nailed it dead cold.

\section{END NoTES}

1. Both of the United States Army Publications: Infantry Drill Regulations of 1904 (56); andThe Basic Field Manual U.S. Rifle Caliber .30 of 1940 instruct on only using the safety lock of the Springfield, and "under no circumstances should the firing pin be let down by hand on a cartridge in the chamber" (Basic 12). The safety lock on the Springfield is easily functioned silently, and one-handed and is perplexing why Hemingway used the slower and unsafe cocking knob of the rifle, requiring both hands to perform.

\section{REFERENCES}

1. Baker, Carlos. Ernest Hemingway: A Life Story. Scribner's, 1969.

2. -----Hemingway: The Writer as Artist. U of Princeton P, 1980.

3. Calabi, Silvio, et al. Hemingway's Guns: The Sporting Arms of Ernest Hemingway. National Book Network, 2010.

4. Clark, Robert C. "Papa y El Tirador: Biographical Parallels in Hemingway's 'I Guess Everything Reminds You of Something."' The Hemingway Review, vol. 27, no. 1, Fall 2007, pp. 89-106.

5. Coté, William E. “Correspondent or Warrior?: Hemingway’s Murky World War II “Combat” Experience." The Hemingway Review, vol. 22, no. 1, Fall 2002, pp. 88-104.

6. Daiker, Donald A. "In Search of the Real Nick Adams: The Case for 'A Very Short Story."” The Hemingway Review, vol. 32, no. 2, Spring 2013, pp. 28-41.

7. Dirty Harry. Directed by Don Siegel, Warner Bros., 1971.

8. Dudley, Marc. "Killin'em with Kindness: "The Porter" and Hemingway's Racial Cauldron." The Hemingway Review, vol. 29, no. 2, Spring 2010, pp. 28-45.

9. Fantina, Richard. "Hemingway's Masochism, Sodomy, and the Dominant Woman" The Hemingway Review. vol. 23, no. 1, Fall 2003, pp. 84-105.

10. Farah, Andrew. Hemingway's Brain. U of South Carolina P, 2017.

11. Gardener, Carol Hemingway. "Recollections." The Hemingway Review, vol. 24, no. 1, Fall 2004, pp. 17-31.

12. Hemingway, Ernest. Across the River and into the Trees. Scribner, 2003.

13. -----A Farewell to Arms. Scribner's, 1957.

14. -----For Whom the Bell Tolls. Scribner's, 1940.

15. -----Green Hills of Africa. Scribner, 2015.

16. -----Islands in the Stream. Collins, 1970.

17. -----Selected Letters 1917-1961. Edited by Carlos Baker, Scribner's, 1981.

18. -----The Complete Short Stories of Ernest Hemingway: The Finca Vigía Edition, Scribner, 1987.

19. -----To Have and Have Not. Collier \& Son, 1937.

20. -----Under Kilimanjaro. Edited by Robert W. Lewis, Robert E. Fleming, U of Kent State P, 2005. 
A Culture of Guns: Firearms a Key Feature of the Hemingway Narrative and Persona

21. Hemingway, Leicester. My Brother, Ernest Hemingway. The World Publishing Company, 1962.

22. Hotchner, A. E. Papa Hemingway. Random, 1966.

23. Meredith, James Hughes. "Bird Hunting and Male Bonding in Hemingway's Fiction and Family." Hemingway and the Natural World, edited by Robert E. Fleming, U of Idaho P, 1999, pp. 189-201.

24. Meyers, Jeffrey. Hemingway: A Biography. Da Capo Press. New York, 1999.

25. Risch, Robert. "Evan Shipman: Friend and Foil.” The Hemingway Review, vol. 23 , no. 1, Fall 2003, pp. 4257.

26. Roosevelt, Theodore. African Game Trails: An Account of the African Wanderings of an American HunterNaturalist. Scribner's, 1910.

27. Stagecoach. Directed by John Ford, United Artists, 1939.

28. Time. vol. XXX, no. 16, October, 1937.

29. United States War Department. Basic Field Manual U. S. Rifle, Caliber .30, M1903. FM 23-10. U.S. Government Printing Office, 1940.

30. -----Infantry Drill Regulations, United States Army. 1904.

31. Voss, Frederick. Picturing Hemingway: A Writer in His Time. U of Yale P, 1999.

32. Wanted Dead or Alive. Directed by Thomas Carr. Et al, CBS, 1958-1961.

33. Young, Philip. Ernest Hemingway: A Reconsideration. Harcourt, Brace \& World, Inc., 1966.

Citation: Neil L. R. Tate, "A Culture of Guns: Firearms a Key Feature of the Hemingway Narrative and Persona" American Research Journal of English and Literature, vol 5, no. 1, 2019, pp. 1-15.

Copyright (C) 2019 Neil L. R. Tate, This is an open access article distributed under the Creative Commons Attribution License, which permits unrestricted use, distribution, and reproduction in any medium, provided the original work is properly cited. 